\title{
SCIDOC
}

International Journal of Dentistry and Oral Science (IJDOS)

ISSN: 2377-8075

\section{Comparing The Effectivenes Of Chlorhexidine Gel And Metronidazole Gel In Management Of Dry Socket}

Research Article

\author{
J Jayaindhraeswaran ${ }^{1 *}$, Senthil Nathan $\mathrm{P}^{2}$, Arun $\mathrm{M}^{3}$ \\ ${ }^{1}$ Department of Oral \& Maxillofacial Surgery, Saveetha Dental College, Saveetha Institute of Medical and Technical Sciences, Saveetha University, \\ Chennai 600 077, Tamilnadu, India. \\ ${ }^{2}$ Professor, Department of Oral \& Maxillofacial Surgery, Saveetha Dental College, Saveetha Institute of Medical and Technical Sciences, Saveetha \\ University, Chennai 600 077, Tamilnadu, India. \\ ${ }^{3}$ Senior lecturer, Department of Oral \& Maxillofacial Surgery, Saveetha Dental College, Saveetha Institute of Medical and Technical Sciences, Saveetha \\ University, Chennai, India.
}

\section{Abstract}

\begin{abstract}
Aim: To compare and analyse the effectiveness of the intra alveolar application of chlorhexidine gel and metronidazole gel in management of dry socket.

Materials And Method: In vivo, single blind ,randomised control through comparative protective study was conducted in the Department of oral and maxillofacial surgery. Around 30 patients were included in study irrespective of their gender, race and they had undergone extraction of third molar successively. Patients were in the age group of 18-40 years. The patients were divided into two groups of 15 patients each based on study material used. Patient were evaluated for mouth opening, facia size during pre-operative study, followed by 3 rd and 7 th day post operatively.

Result: The study clearly shows us a reasonable improvement in the mouth opening and swelling after placement of metronidazole gel.In addition to effectiveness there is decrease in post extraction pain particularly due to usage of metronidazole gel. Conclusion: This study particularly emphasise upon usage of metronidazole gel because of its effectiveness in reducing post operative complication like pain, swelling and reduction in mouth opening. This tangible improvement signifies and highlights the use of metronidazole in the prevention of dry socket after third molar extraction.
\end{abstract}

Keywords: Chlorhexidine Gel; Dry Socket; Third Molar Extraction; Metronidazole Gel.

\section{Introduction}

Dry socket or alveolar osteitis is a very painful per se, self limiting condition which is relatively common complication following the tooth extraction process. Dry socket was first described in 1896 by Crawford. According to Blum, Dry socket is defined as pain near the extraction socket after post operation, which increase in intensity at any time between the first and third day after extraction of third molar. This particular complication which occur due to partially or totally disrupted blood clot within socket and also with or without halitosis. This incidence varies between $20 \%$ to $30 \%$ after extraction of impacted third molar and $1 \%$ to $80 \%$ for all dental extraction. The onset of dry socket occur 1 to 3 days after toothextraction. Etiology of dry socket has not been firmly known as of now, two main theories have been proposed for the ethology of dry socket. Current cure resides with antibacterial agents, antiseptics, antifibrinolytics, anti inflammatory agents. Antiseptics such as chlorhexidine rinses proved to be highly efficient in dry socket prevention and its complication.

The study was prospective ,blind study done to assess and compare the effectiveness of chlorhexidine gel and metronidazole gel placed directly into surgical socket after removal of extraction third molar.

Previously our team has a rich experience in working on various research projects across multiple disciplines (Govindaraju and Gurunathan 2017; A. Christabel et al. 2016; Soh and Naray-

*Corresponding Author:

J Javaindhraeswaran,

Department of Oral \& Maxillofacial Surgery, Saveetha Dental College, Saveetha Institute of Medical and Technical Sciences, Saveetha University, Chennai 600 077, Tamilnadu, India. Tel: 7200500633

E-mail: eshwaran.jijigmail.com

Received: April 25, 2021

Accepted: July 09, 2021

Published: July 21, 2021

Citation: J Jayaindhraeswaran, Senthil Nathan P, Arun M. Comparing The Effectivenes Of Chlorhexidine Gel And Metronidazole Gel In Management Of Dry Socket. Int J Dentistry Oral Sci. 2021;8(7):3457-3459. doi: http://dx.doi.org/10.19070/2377-8075-21000705

Copyright: J Jayaindhraeswaran ${ }^{2021}$. This is an open-access article distributed under the terms of the Creative Commons Attribution License, which permits unrestricted use, distribution and reproduction in any medium, provided the original author and source are credited. 
anan 2013; Mehta et al. 2019; Ezhilarasan, Apoorva, and Ashok Vardhan 2019; Campeau et al. 2014; Kumar and S 2016; S. L. Christabel 2015; Kumar and Rahman 2017; Sridharan, Ramani, and Patankar 2017; Ramesh et al. 2016; Thamaraiselvan et al. 2015; Thangaraj et al. 2016; Ponnulakshmi et al. 2019; "Fluoride, Fluoridated Toothpaste Efficacy and Its Safety in Children - Review" 2018) Now the growing trend in this area motivated us to pursue this project.

\section{Materials And Methods}

This study involved both male and female patients, who were under went molar extraction with difficulty score ranging between 7 to 10 in Pederson difficulty index.

\section{Inclusion Criteria}

All the patient in the age group of $18-40$ years, requiring extraction of 3 rd molar.

\section{Exclusion Criteria}

- Patients with immuno compromized patients

- Pregnancy patients and oral contraceptive
- Patients allergic to chlorhexidine and metronidazole

- Patients with hard or soft tissue pathology

- Patients who are addicted or abuse alcohol and tobacco.

\section{Study Design}

Study conducted based on 30 participants and they were divided into two groups based on the material applied in the dry socket .All the patients underwent extraction with the same techniques. All the necessary procedures were done with the help of local anesthesia i.e, with $2 \%$ lignocaine by the same practitioner to eliminate any bias in the procedure. Patients were reviewed on the 3rd day and second review on 7 th day post operation.

\section{Discussion}

The most common and painful complication in the healing process of the extraction wound is Dry socket. Alveolar osteitis is an acute non purulent inflammatory process. It is localised in the dental alveolus that creates a delay in wound healing. Its characters include late onset with intense and irradiating pain. The main characteristic of the extraction socket is the denuded appearance. The interior bone exposed in the oral cavity which is whitish. Most crucially it is hypersensitive to contact. Most literature supports

Figure 1. Distribution of male and female in each group.

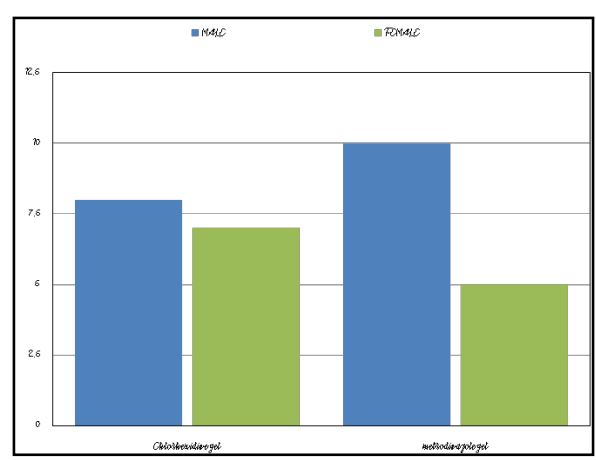

Table 1. Mean and $\mathrm{p}$ value for pain.

\begin{tabular}{|c|c|c|c|}
\hline $\begin{array}{c}\text { Based on difficulty } \\
\text { index }\end{array}$ & Pain on 3 rd day & Pain on 7th day & $\begin{array}{c}\text { Chi square } \\
\text { (P value) }\end{array}$ \\
\hline GROUP & No pain mild moderate & No pain mild moderate & 3rd day 7th day \\
\hline Chlorhexidine gel & 087 & 069 & 0.0320 .007 \\
\hline Metrodinazole gel & 672 & 1041 & 0.0250 .004 \\
\hline
\end{tabular}

Table 2. Mean and $\mathrm{p}$ value for facial size.

\begin{tabular}{|c|c|c|c|c|c|}
\hline Based on diffi- & Based on case & Facial & Facial size on the & Facial size on & Paried $\mathbf{t}$ Test \\
\cline { 5 - 6 } & group & size pre & 3rd day & the 7th day & 3rd day 7th day \\
\hline GROUP & Chlorhexidine gel & 11.5 & 12.65 & 12.3 & 0.7820 .670 \\
\hline & Metrodinazole gel & 11.45 & 11.95 & 11.6 & 0.6540 .560 \\
\hline
\end{tabular}

Table 3. Mean and $\mathrm{p}$ value for mouth opening.

\begin{tabular}{|c|c|c|c|c|c|}
\hline $\begin{array}{c}\text { Based on dif- } \\
\text { ficulty index }\end{array}$ & $\begin{array}{c}\text { Based on case } \\
\text { group }\end{array}$ & $\begin{array}{c}\text { Mouth open- } \\
\text { ing pre } \mathbf{( m m )}\end{array}$ & $\begin{array}{c}\text { Mouth opening on } \\
\text { the 3rd day(mm) }\end{array}$ & $\begin{array}{c}\text { Mouth opening on } \\
\text { the 7th day(mm) }\end{array}$ & Paried t Test \\
\hline GROUP & Chlorhexidine gel & 38.5 & 30 & 34 & 0.0270 .045 \\
\hline & Metrodinazole gel & 38 & 32 & 36 & 0.0100 .00 \\
\hline
\end{tabular}


that dry socket occurs very infrequently in childhood and that incidence increase with increase in patients age. In this study, there exist no correlation between gender, age, site of extraction and dry socket.

In 1977, Legarth performed a study to see the effect of $0.2 \%$ chlorhexidine on dry socket prevention and noted a $45 \%$ decrease in dry socket in a group of 60 patients. The bio adhesive $0.2 \%$ chlorhexidine gel directly placed into socket will have more direct action on the alveolus.

Various studies have been done to see the major role of metronidazole in the prohibition of dry socket. And its results were found, which says prophylactic metronidazole was found to be effective means of preventing dry socket after regular dental extraction.

The antimicrobial activity of metronidazole has been proposed is due to the reduction of nitro group to a more reactive amine group. This amine group attacks the microbial DNA thus inhibiting further synthesis and causing degradation of existing DNA .From the mentioned mechanism of action use of ornidazole as local drug delivery may be an advantageous form of treatment since it would probably eliminate side effects.

By taking into account clinical evaluation and statistical analysis we found that in patient were intra alveolar metronidazole gel was placed there was significant decrease in pain on the $3 \mathrm{rd}$ day post operative and 7 th day post operative day. Mouth opening and facial swelling was also reasonable post operative. At the end comparison of chlorhexidine gel and metronidazole gel irrespective of Peterson difficulty index score for mouth opening, facial size and pain, there is statistically significant, from this it can be concluded that metronidazole gels are effective in reducing post extraction complications.

Our institution is passionate about high quality evidence based research and has excelled in various fields ( Jayaseelan Vijayashree
Priyadharsini 2019; Pc, Marimuthu, and Devadoss 2018; Ramesh et al. 2018; Ramadurai et al. 2019; Sridharan et al. 2019; Ezhilarasan, Apoorva, and Ashok Vardhan 2019; Mathew et al. 2020; Samuel 2021; R et al. 2020; Chandrasekar et al. 2020; J. Vijayashree Priyadharsini, Smiline Girija, and Paramasivam 2018)

\section{Conclusion}

This study indicates that irrespective of difficulty index, metronidazole gel is effective in decreasing the post operative complications which includes pain, swelling and reduction in mouth opening.The limitation of the present study is small sample size.

\section{References}

[1]. Peterson D. Dry Socket. Br J Dent 2003; 194: 453-5.

[2]. Nusair YM, Younis MH. Prevalence, clinical picture, and risk factors of dry socket in a Jordanian dental teaching center. J Contemp Dent Pract. 2007 Mar 1;8(3):53-63. Pubmed PMID: 17351682.

[3]. Peterson LJ, Ellis E Ill, Hupp JR, Tucker MR. Contemporary oral and maxillofacial surgery. 4th ed. USA: Mosby 2003; 236-7.

[4]. Rood JP, Murgatroyd J. Metronidazole in the prevention of 'dry socket'. British journal of oral surgery. $1979 \mathrm{Jul}$ 1;17(1):62-70.

[5]. Bonine FL. Effect of chlorhexidine rinse on the incidence of dry socket in impacted mandibular third molar extraction sites. Oral Surg Oral Med Oral Pathol Oral Radiol Endod. 1995 Feb;79(2):154-7; discussion 157-8. Pubmed PMID: 7614176.

[6]. Amaratunga NA, Senaratne CM. A clinical study of dry socket in Sri Lanka. Br J Oral Maxillofac Surg. 1988 Oct;26(5):410-8. Pubmed PMID: 3056513.

[7]. Anand SC, Singh VD, Goel M, Verma A, Rai B. Dry socket an appraisal and surgical management. The Internet Journal of Dental Science. 2007;13(1):53-8.

[8]. Alexander RE. Dental extraction wound management: a case against medicating postextraction sockets. J Oral Maxillofac Surg. 2000 May;58(5):53851. Pubmed PMID: 10800910.

[9]. Birn H. Etiology and pathogenesis of fibrinolytic alveolitis ("dry socket"). International journal of oral surgery. 1973 Jan 1;2(5):211-63.

[10]. Blum IR. Contemporary views on dry socket (alveolar osteitis): a clinical appraisal of standardization, aetiopathogenesis and management: a critical review. Int J Oral Maxillofac Surg. 2002 Jun;31(3):309-17. Pubmed PMID: 12190139. 